\title{
StoryGirl: programando através de narrativas
}

\author{
Beatriz Saburido $^{1}$, Angélica F. S. Dias ${ }^{4,5}$ e Juliana B. S. França ${ }^{1,2,3}$ \\ ${ }^{1}$ Departamento de Computação (DECOMP/UFRRJ) - RJ, Brasil \\ ${ }^{2}$ Programa de Pós-Graduação PPGMMC/UFRRJ - RJ, Brasil
}

${ }^{3}$ Programa de Pós-Graduação em Gestão e Estratégia (PPGE/UFRRJ) - RJ, Brasil

${ }^{4}$ Instituto Tércio Pacitti de Aplicações e Pesquisas Computacionais (NCE/UFRJ), Brasil

${ }^{5}$ História das Ciências e das Técnicas e Epistemologia (HCTE/UFRJ), Brasil

\{saburido57, angelicafsdias, julibsf\}@gmail.com

\begin{abstract}
Over the years, the number of women working in STEAM's areas (Science, Technology, Engineering, the Arts and Mathematics) has decreased around the world. In Brazil, this reflex is observed at the entrance of higher education courses in technology, which receive fewer and fewer women each year. With the importance of promoting the entry of women in undergraduate courses in technology in Brazil, especially in the state of Rio de Janeiro, this paper presents an initiative proposed by an extension project. In it, girls between 11 and 15 years old go to the logical structures of scratch programming and are oriented to program the scenarios of their real or fictional narratives. The results achieved are promising.
\end{abstract}

Resumo. Ao longo dos anos, tem-se observado a diminuição do número de mulheres que trabalham com áreas associadas ao STEAM (Science, Technology, Engineering, the Arts and Mathematics). No Brasil, este reflexo é instanciado já na entrada dos cursos de nível superior em tecnologia, que a cada ano recebem cada vez menos mulheres. Com a finalidade de fomentar a entrada de mulheres nos cursos de graduação em tecnologia no Brasil, este artigo apresenta a iniciativa proposta por um projeto de extensão universitária. Nele, meninas entre 11 e 15 anos são apresentadas às estruturas lógicas de programação em scratch e são orientadas a programarem os cenários de suas narrativas reais ou fictícias. Os resultados atingidos são promissores.

\section{Introdução}

A concentração de mulheres profissionais na área de Tecnologia da Informação (TI) tem diminuído drasticamente ao longo dos anos. Este fato tem despertado a atenção mundial por meio de governos, empresas e instituições de ensino [PISA, 2015], a fim de que estratégias sociais possam intervir a fim de promover a diversidade de gênero na área de TI. Segundo a ONU [ONU, 2015] a igualdade de gênero é um dos 17 objetivos a ser alcançado com a finalidade de mudar o mundo habitado e desenvolvido por humanos. De acordo com os dados do IBGE de 2013, no Brasil, a população feminina é estimada em $51 \%$, totalizando um indicativo maior de mulheres do que homens [Ribeiro et. al., 2019]. No entanto, é fato notório que as mulheres representam o quantitativo com menor valor salarial em seus cargos e menor reconhecimento profissional. 
Essa mesma estatística se estende para a área de computação. Dados de 2007 mostram que apenas $24,05 \%$ dos atuantes em computação no mercado de trabalho formal no Brasil são do gênero feminino. Em 2017 esse percentual caiu ainda mais para $19,83 \%$. Esses percentuais fazem das mulheres minoria na computação e, portanto, tem motivado diferentes iniciativas para tornar essa distribuição de gênero mais homogênea nos âmbitos educacional e profissional [Softex, 2019], [Cardoso and David, 2016].

De acordo com [Medeiros, 2005] (ativista em discussões e pesquisas sobre gênero e computação), a sociedade brasileira precisa estimular as mulheres a se tornarem agentes ativas em uma sociedade movida pela informação, tecnologia e inovação. Em sua visão, este incentivo está em reconsiderar a estrutura educacional, desenvolver novos conteúdos, e considerar as estratégias educacionais que atendam as meninas ainda em sua formação básica na infância. Dessas estratégias, observam-se pesquisas que já vêm rompendo barreiras quanto à equidade de gênero no Brasil [Frigo et al., 2020], [Santana et al., 2020].

Dessa maneira, este artigo apresenta resultados de um Projeto de Extensão inserido em uma Universidade Federal do Brasil, com o objetivo de apresentar às meninas, em idade de 11 a 15 anos, o universo da programação de computadores. Neste projeto é aplicado o Scratch, linguagem de programação em blocos de fácil orientação para crianças. Com este projeto, espera-se manter o interesse técnico e emocional da criança em programar as narrativas que chamam a sua própria atenção. Objetivamente, este artigo apresenta os primeiros resultados alcançados em um estudo piloto da estratégia proposta, além da preparação e condução das sessões de interação com as crianças.

Este artigo é organizado considerando a Seção 2 com a discussão do arcabouço científico nacional sobre o Ensino de programação para crianças e adolescentes. Na seção 3, a construção e estrutura do Projeto StoryGirl e as oficinas já conduzidas. Na conclusão, são apresentadas as contribuições do estudo e os próximos passos desta iniciativa frente às atividades do projeto de extensão e à pesquisa científica associada.

\section{Ensino da Programação de Computadores para Crianças e Adolescentes}

Pesquisas recentes discutem as contribuições de iniciativas que fomentem a inserção de mulheres nas áreas que envolvem o STEAM [Santos and Oliveira, 2020]. Muitas delas defendem o design e execução de estratégias que atinjam meninas em sua fase de vida infanto-juvenil. Isso ocorre porque acredita-se que influências sociais e culturais contribuem para o desenvolvimento cognitivo e novos saberes das crianças.

A literatura mostra que a linguagem de programação em blocos tem sido amplamente utilizada com o público infantil com o objetivo de desenvolver o pensamento computacional em crianças [França and Tedesco, 2019]. Há também pesquisas que discutem o desenvolvimento do pensamento computacional no público feminino, que tem sofrido com uma baixa presença na área de computação [Marquiori et al., 2019]. Traçando o mapeamento simplificado de estratégias que conduzem o ensino da programação de computadores em scratch através de narrativas (uso da técnica storytelling), pode-se destacar [Farias et al. 2019].

\section{Projeto StoryGirl}

O Projeto foca na inserção de meninas entre 11-15 anos de escolas públicas e privadas no universo STEAM. Para isso, busca-se desenvolver competências lógicas de programação através de narrativas de histórias de interesse desse público. Entende-se que estas ações 
podem promover o desenvolvimento do raciocínio lógico e pensamento computacional ainda na fase primária de educação das meninas, estimulando este gênero no interesse às áreas exatas. Este projeto visa também contribuir com a transformação cultural das meninas, estimulando nelas o interesse na área de exatas e fomentando a entrada de meninas nos cursos de graduação em áreas afins ao projeto.

O programa articula ações de pesquisa, onde serão estudadas as formas mais indicadas de estruturar e ensinar através de histórias os conteúdos lógicos de programação de forma colaborativa. Através do uso e adaptação de técnicas de visualização existentes, esperamos chegar a soluções com explicações intuitivas e que aumentem a compreensão das meninas sobre as estruturas lógicas contidas em suas histórias. Durante o desenvolvimento do projeto serão conduzidos oficinas e debates sobre o papel das mulheres na ciência. Serão produzidos meios de disseminação do pensamento lógico, introduzindo soluções programáveis e apresentando técnicas de programação em linguagens de fácil entendimento para crianças como o Scratch.

Diante deste cenário, este projeto visa estimular meninas e jovens no desenvolvimento de suas habilidades lógicas, computacionais e pensamento crítico sobre suas narrativas. Espera-se trabalhar com histórias que traduzam as experiências dessas meninas no âmbito lúdico, social ou escolar. Com base nos cenários programados sobre as experiências pessoais das meninas, espera-se projetar futuramente um ambiente colaborativo de troca de conhecimentos e experiências. Resumidamente, o presente projeto é motivado por: (i) Influenciar meninas e jovens nas áreas envolvidas no STEAM; (ii) Habilitar as meninas a extraírem conhecimento de narrativas através dos cenários programados; (iii) Propor iniciativas que envolvem estratégias de ensino-aprendizagem de programação através de cenários; (iv) Capacitação de alunos da graduação para atuação como tutores das meninas do ensino básico. Este projeto é organizado em quatro fases que serão executadas ciclicamente a cada nova turma de crianças atendidas. As fases previstas são: planejamento da oficina, oficina, programação dos cenários e compartilhamento de experiências. $O$ objetivo é que a cada nova iteração, os artefatos produzidos sejam melhorados e as dinâmicas de condução das oficinas com as crianças sejam melhoradas.

\subsection{Estudo Piloto}

O projeto começou a ser pensado em 2019, mas ganhou forma em 2020. Como é conhecido, o ano de 2020 foi atípico e mudanças foram necessárias quanto ao desenvolvimento das atividades do projeto. Neste ano foram concentradas as atividades de produção do material da oficina e preparação dos tutores. Ainda em 2020 aconteceu um teste piloto com cinco crianças, isoladamente, com a finalidade de testar o material produzido. Já em 2021 o projeto foi conduzido em uma primeira turma oficial, embora ainda não associada diretamente a uma escola. É importante destacar que em função da pandemia, todas as atividades que aconteceram no projeto de 2020 até o momento foram no ambiente virtual.

A primeira iniciativa de avaliação da estrutura do projeto e material produzido para as oficinas aconteceu em 2020. Nela foi investigada a viabilidade de explorar na teoria e na prática os conceitos das estruturas básicas da lógica de programação. Neste estudo, seis crianças foram convidadas a relatarem suas histórias reais e três delas foram programadas em Scratch. As histórias, neste estudo piloto, foram programadas pelas 
tutoras deste projeto a fim de investigar as potencialidades das histórias reais em explorar recursos básicos da programação em blocos. As histórias programadas neste estudo exploraram conceitos similares envolvidos no pensamento computacional do aprendiz e, consequentemente, na programação básica de computadores ${ }^{1}$. Esta primeira avaliação deixou clara a possibilidade de explorar as estruturas simples de programação em cenários de histórias. A fase seguinte do projeto buscou investigar se as crianças e adolescentes, participantes da oficina de programação, são capazes de programar suas próprias histórias, tendo como suporte em seu processo de aprendizagem os demais participantes da oficina e os tutores envolvidos no projeto.

\subsection{Primeira Oficina do Projeto}

Nesta fase do estudo houve a participação de 8 meninas, entre 11 e 15 anos, alunas do $6^{\circ}$ ao $1^{\circ}$ ano do ensino médio de diferentes escolas do setor privado do Rio de Janeiro. Esta oficina ocorreu em formato remoto, dividida em dois encontros com duas horas de duração em março de 2021. No primeiro encontro foram apresentados conceitos básicos da programação de computadores como repetição e condição, sequência lógica de ação, cenários, variáveis, interação entre objetos, eventos e atores. Ainda no primeiro encontro foram conduzidas discussões sobre a inserção de mulheres na área da computação, e onde a programação de computadores é observada no dia a dia de todo indivíduo. No segundo encontro, as participantes apresentaram seus projetos e discutiram as facilidades e dificuldades no processo da programação em blocos.

\section{Conclusão}

O presente artigo apresentou os resultados obtidos com a aplicação da primeira oficina do projeto. Este tem por objetivo apresentar a programação de computadores para meninas através da linguagem de programação em Scratch fomentando a sua inserção em áreas envolvidas no STEAM. O diferencial desta ação é a introdução de conceitos básicos de programação através de narrativas. O resultado atingido com a oficina mostra o interesse das meninas pela programação, e a viabilidade de introdução das estruturas básicas de programação através da programação de cenários das histórias trazidas pelos participantes.

Como ponto de atenção sobre os resultados alcançados, destacam-se a familiaridade das meninas participantes com o Scratch e a interação ensino-aprendizagem delas em escolas do setor privado. Como próximos passos desta iniciativa, espera-se conseguir rodar em turmas nas escolas do setor público e privado, no formato online ou presencial. Espera-se também investigar a aplicabilidade desta mesma iniciativa com meninas da mesma faixa-etária, mas sem contato prévio com o Scratch. Ainda como desdobramento dessa iniciativa, espera-se criar uma rede colaborativa de apoio técnico e social com base nas histórias programadas.

\section{Agradecimentos}

Esta pesquisa recebeu apoio da FAPERJ - E-26/211.367/2019 (248406).

\footnotetext{
${ }^{1}$ https://scratch.mit.edu/projects/412636110/

https://scratch.mit.edu/projects/412324336

https://scratch.mit.edu/projects/412481871/
} 


\section{Referências}

Cardoso, É. E. C., \& de David, T. (2016). A falta de profissionais de tecnologia de informação no mercado de trabalho. Uma Nova Pedagogia para a Sociedade Futura, 697700 .

Farias, C., da Cruz, V. G., Farias, J. S., Braz, D. C., Brito, B. M., \& de Souza Carvalho, A. (2019, November). Estimulando o Pensamento Computacional: uma experiência com ScratchJr. In Anais do Workshop de Informática na Escola (Vol. 25, No. 1, p. 197).

França, R., \& Tedesco, P. (2019, November). Pensamento Computacional: Panorama dos Grupos de Pesquisa no Brasil. In Brazilian Symposium on Computers in Education (Simpósio Brasileiro de Informática na Educação-SBIE) (Vol. 30, No. 1, p. 409).

Frigo, L. B., Moro, F. F., Padilha, R. O.,Pozzebon , E.. Meninas em Ação Atividades Inspiradoras para Projetos Parceiros do Programa Meninas Digitais. In: Anais do XI Women In Information Technology (WIT 2020), Congresso da Sociedade Brasileira de Computação (CSBC 2020). Disponível em: https://sol.sbc.org.br/index.php/wit/article/view/11276. Acessado em: 15 de Abril de 2021.

Marquiori, V., Oliveira, M., \& Nascimento, G. (2019, July). Letramento de Meninas em Programação através do Pensamento Computacional para Compreensão de Problemas. In Anais do XIII Women in Information Technology (pp. 109-113). SBC.

Medeiros, C. B. (2005). From subject of change to agent of change: women and IT in Brazil. In Proc. of the International Symposium on Women and ICT: creating global transformation (CWIT '05), C. Morrell and J. Sanders (Eds.). ACM, New York, NY, USA, Article 15.

Organização das Nações Unidas (ONU). (2015). Programa das Nações Unidas para o desenvolvimento (PNUD). Objetivos do Desenvolvimento Sustentável. Disponível em: https://nacoesunidas.org/pos2015/ods5/.

PISA. 2015. O que está por trás da desigualdade de gênero na educação? OCDE. Acessado em 15/04/2021.

Ribeiro, L., Barbosa, G., Silva, I., Coutinho, F., \& Santos, N. (2019, July). Um Panorama da Atuação da Mulher na Computação. In Anais do XIII Women in Information Technology (pp. 1-10). SBC.

Santana, T. S.; Braga, A. H. Uma Análise Cienciométrica das Publicações do Congresso da Sociedade Brasileira de Computação na Perspectiva das Mulheres na Computação. In: Anais do XIV Women In Information Technology (WIT 2020), Congresso da Sociedade Brasileira de Computação (CSBC 2020). Disponível em: https://sol.sbc.org.br/index.php/wit/article/view/11310. Acessado em: 15 de Abril de 2021.

Santos, C., \& Oliveira Filho, A. (2020). Robótica e Interdisciplinaridade: Aprendizagem Criativa Atraindo Meninas para a Tecnologia. In Anais do XIV Women in Information Technology, (pp. 120-128). Porto Alegre: SBC. doi:10.5753/wit.2020.11282

Softex. (2019) Atuação da Mulher no Mercado de Trabalho Formal Brasileiro em Tecnologia da Informação. Arquivo eletrônico disponível em: https://www.ftp.softex.br/Inteligencia/mulheres_na_ti/mulheres_na_ti.pdf. Acessado em: Março 2021. 